\title{
PENGARUH KOMPENSASI DAN BUDAYA ORGANISASI TERHADAP KINERJA TENAGA AHLI PERUSAHAAN JASA KONSULTAN DI PROVINSI JAMBI
}

\author{
Fakhrul Rozi Yamali
}

\begin{abstract}
The purpose of this research is to find out and analyze the effect of compensation and organizational culture either partially or jointly on performace experts at consulting services firm in the province of Jambi. The population in this reseach totalled of 532 people expert at consulting service firm in the of Jambi. The method used in this reseach is a descriptive survey method and sample survey with the spread of eksplanatori at least for three variables as much as 200 respondents. Based on the result of the hypothesis, thought to compensation and organizational culture partially or jointly affect performance experts. The result that explains, the competence variable on the performance of expert is 0.48 and the organizational culture variable on the performance of expert 0.37 to the performance of experts. The effect of jointly compensation (KS) and organizational culture (BO) on the performance of expert $(K A)$ is $0.6053 \approx 0.60$ or is $R^{2}=0.60$ magnitude influence with the influence of $60 \%$
\end{abstract}

Keywords: compensation, organizational culture, performace experts.

\section{PENDAHULUAN}

Indonesia dalam beberapa dekade terakhir ini mengalami kemajuan di segala bidang, banyaknya pembangunan infrastruktur merupakan salah satu ciri menggeliatnya pertumbuhan ekonomi. Pesatnya pembangunan infrastruktur di Indonesia berbanding lurus dengan peningkatan pada bidang jasa konstruksi modern, hal ini bisa kita lihat dengan semakin banyak gedung-gedung bertingkat tinggi, jalan, jembatan, irigasi dan sarana-sarana terkait konstruksi modern dewasa ini. Mengacu kepada UU No. 18 Tahun 1999 tentang jasa konstruksi yang dimaksud dengan jasa konstruksi adalah layanan jasa konsultansi perencanaan pekerjaan konstruksi, layanan jasa pelaksanaan pekerjaan konstruksi, dan layanan jasa konsultansi pengawasan pekerjaan konstruksi. Pekerjaan jasa konsultan adalah bagian dari keseluruhan pekerjaan kontruksi tersebut. Perusahaan jasa konsultan bidang konstruksi di Indonesia saat ini terus mengalami peningkatan dari tahun ke tahun, jumlah badan usaha jasa konsultan (BUJK) baik secara Nasional maupun dalam Provinsi Jambi seperti pada Tabel 1. dibawah ini :

\section{Tabel 1}

\begin{tabular}{|c|c|c|c|c|}
\hline \multicolumn{5}{|c|}{ Badan Usaha Jasa Konsultan Konstruksi di Indonesia } \\
\hline Kualifikasi & $\begin{array}{l}\text { Kecil } \\
\text { Grade } 2\end{array}$ & $\begin{array}{l}\text { Menengah } \\
\text { Grade } 3\end{array}$ & $\begin{array}{c}\text { Besar } \\
\text { Grade } 4\end{array}$ & TOTAL \\
\hline Jumlah BUJK Nasional & 5.071 & 907 & 429 & 6.407 \\
\hline Jumlah BUJK Provinsi Jambi & 120 & 12 & 1 & 133 \\
\hline
\end{tabular}

Sumber: LPJK Nasional, 2017

Tabel 1. di atas mengindikasikan bahwa jumlah Badan Usaha Jasa Konsultan di Indonesia khususnya di Provinsi Jambi lebih di dominasi oleh Jasa konsultan dengan kualifikasi kecil dan menengah, yaitu mencapai $90.23 \%$ dan $9.02 \%$ sementara sisa nya berkualifikasi besar hanya mencapai $0,76 \%$. Dari ketiga grade tersebut menunjukkan bahwa grade kecil menengah mendominasi dan hanya sebagian kecil grade besar pada BUJK bidang jasa konsultan di Indonesia khususnya di Provinsi Jambi. Berdasarkan data LPJK Provinsi Jambi (2016) perusahaan jasa konstruksi berjumlah 3047 perusahaan jasa konstruksi pelaksana maupun jasa konsultansi. Hal ini mengindikasikan bertumbuhnya anggaran dibidang konstruksi.

Jumlah Tenaga Ahli di Provinsi Jambi Pada Tahun 2012 hanya ada 882 orang dengan Sertifikat 1200. Sampai akhir tahun 2016 Jumlah Perusahaan Jasa Konstruksi di Provinsi Jambi meningkat mencapai 3047 Badan Usaha dengan Jumlah Tenaga Ahli sebanyak 1321 Orang. Dalam menangani satu kegiatan pekerjaan konsultan grade 2 minimal membutuhkan 3 orang tenaga ahli, sehingga bila dikalkulasi kebutuhan tenaga ahli 
perusahaan konsultan di Provinsi Jambi berjumlah 532 orang tenaga ahli. Bertumbuh dan berkembangnya anggaran konstruksi dan jumlah pelaku jasa konstruksi khususnya bidang konsultasi seharusnya meningkatkan kinerja tenaga ahli, namun pada kenyataannya kinerja tenaga ahli perusahaan jasa konsultansi di Provinsi Jambi belum mengalami peningkatan. Banyak faktor yang menyebabkan rendahnya kinerja pegawai, menurut hasil penelitian dari Jamil and Sarfaraz, 2011, menyatakan bahwa "The compensation practices are positively and significantly associated with employee performance of public sector organizations". Bahwa kompensasi berpengaruh secara positif dan signifikan terhadap kinerja pegawai sektor publik. Masih dalam Jamil and Sarfaraz 2011, menyatakan pula bahwa tujuan dasar dari setiap organisasi publik adalah untuk mengkompensasi karyawan dalam setiap cara yang mungkin. Sehingga akibatnya organisasi publik yang diluncurkan untuk menciptakan lapangan kerja. Orang yang memiliki gelar atau keahlian dalam satu bidang dan dapat bekerja di bidang lain karena alasan yang berbeda. Oleh karena itu kompensasi adalah entitas utama yang mempengaruhi kinerja karyawan. Sementara itu Tahir Masood Qureshi et al. (2010) melakukan studi empiris tentang dampak praktek HRM terhadap kinerja pegawai bank di Pakistan berdasarkan sistem reqruitment, pelatihan, sistem penilaian kinerja, sistem kompensasi, sistem perencanaan karir dan partisipasi karyawan. Semua praktek-praktek yang berhubungan positif dengan kinerja pegawai. Tetapi sistem seleksi, pelatihan, kompensasi dan partisipasi karyawan memiliki pengaruh kuat pada kinerja pegawai bank-bank.

Berdasarkan kedua hasil penelitian di atas, maka rendahnya kinerja tenaga ahli perusahaan jasa konsultan di Provinsi Jambi cenderung disebabkan oleh masih relatif rendahnya kompensasi tenaga ahli pada perusahaan jasa konsultan. Rendahnya tingkat kompensasi tenaga ahli perusahaan jasa konstruksi di Provinsi Jambi berpengaruah terhadap rendahnya kompensasi jasa konsultan, hal ini diindikasikan berdasarkan pada hasil observasi langsung peneliti FR Yamali (2017) pada penelian terdahulu didapat beberapa tenaga ahli dari beberapa perusahaan jasa konsultan, rata-rata tenaga ahli pada setiap kelompok ahli dan golongan serta jenjang pendidikan (S1, S2 dan S3) yang terdiri dari ahli muda, ahli madya, dan ahli utama yang hanya memperoleh imbalan secara umum sebesar 30\% dari basic gaji setelah dikali 0,907 (index provinsi Jambi) dari ketentuan Surat Edaran Menteri Pekerjaan Umum No. 22 Tahun 2007, seperti terlihat pada Tabel 2 di bawah ini.

Tabel 2.

Biaya Langsung Tenaga Ahli Jasa Konstruksi

\begin{tabular}{|c|c|c|c|c|}
\hline \multirow[b]{2}{*}{ No. } & \multicolumn{2}{|c|}{ Pendidikan Tenaga Ahli } & \multirow{2}{*}{$\begin{array}{c}\text { S1 } \\
\text { Rupiah/Bulan (x 1000.000) }\end{array}$} & \multirow{2}{*}{$\begin{array}{c}\mathbf{S 2} / \mathbf{S 3} \\
\text { Rupiah/Bulan (x } \\
1000.000)\end{array}$} \\
\hline & Kelompok Ahli & $\begin{array}{c}\text { Tahun Pengalaman } \\
\text { Profesional }\end{array}$ & & \\
\hline 1 & Ahli Muda & $1-4$ & $7,50-10,00$ & $11,45-14,55$ \\
\hline 2 & Ahli Madya & $5-8$ & $10,90-13,70$ & $15,55-18,60$ \\
\hline 3 & Ahli Utama & $9-12$ & $14,60-17,35$ & $19,65-22,70$ \\
\hline
\end{tabular}

Sumber: Surat Edaran Menteri Pekerjaan Umum No. 22 Tahun 2007

Awadh and Saad 2013, berdasarkan pada hasil penelitiaanya menyatakan bahwa "The organization culture helps in internalizing joint relationship that leads to manage effective organization processes. The productivity and culture of organization helps in improving performance". Bahwa budaya organisasi membantu dalam internalisasi hubungan bersama yang mengarah untuk mengelola proses organisasi yang efektif. Produktivitas dan budaya organisasi membantu dalam meningkatkan kinerja. Sehingga berdasarkan kedua pernyataan di atas, maka rendahnya kinerja tenaga ahli perusahaan jasa konstruksi di Provinsi Jambi cenderung disebabkan juga oleh masih relatif kurang baiknya budaya organisasi yang mendukung perusahaan jasa konsultan.

Berdasarkan uraian latar belakang penelitian di atas, maka dapat ditentukan identifikasi masalah anatar lain, 1). Pertumbuhan badan usaha jasa konsultan konstruksi di Provinsi Jambi belum mampu di imbangi dengan peningkatan kinerja dari jasa konstruksi. 2). Rendahnya kinerja tenaga ahli jasa konsultan konstruksi di Provinsi Jambi diduga oleh masih rendahnya kompensasi yang diterima tenaga ahli, hal ini diindikasikan oleh ketidak sesuaian gaji dasar serta kompensasi finansial lainnya seperti insentif dan bonus tahunan ratarata dengan harapan tenaga ahli. 3). Rendahnya kompensasi tenaga ahli perusahaan jasa konsultan konstruksi 
di Provinsi Jambi di indikasikan juga oleh kompensasi non finansial, dimana kompensasi finansial tidak langsung masih relatif rendah seperti tunjangan cuti tahunan, tunjangan pensiun, tunjangan profesi dan tunjangan pelatihan. 4). Rendahnya kinerja tenaga ahli perusahaan jasa konsultan konstruksi di duga oleh masih rendahnya budaya organisasi perusahaan jasa konsultan, hal ini diindikasikan dengan banyak ditemukannya permasalahan menyangkut penyimpangan pada proses tender atau pelelangan, yang pada akhirnya mengakibatkan kegagalan bangunan dan mutu konstruksi yang tidak sesuai standar teknis dan akibat penyimpangan pada proses tender tersebut cukup banyak penunjukkan pemenang yang belum berkualitas.

Tujuan penelitian ini dilakukan untuk mengetahui dan menganalisis: 1). Pengaruh kompensasi tenaga ahli terhadap kinerja tenaga ahli perusahaan jasa konsultan. 2). Pengaruh budaya organisasi terhadap kinerja tenaga ahli perusahaan jasa konsultan. 3). Pengaruh kompensasi tenaga ahli dan budaya organisasi secara bersama-sama terhadap kinerja tenaga ahli perusahaan jasa konsultan.

\section{Tinjauan Pustaka \\ Kompensasi}

Dessler (2005) dalam FR Yamali (2017), mendefinisikan Kompensasi adalah sebagai segala bentuk pembayaran atau imbalan yang diberikan kepada karyawan yang timbul dari pekerjaan mereka. Sehingga kompensasi merupakan salah satu alasan dasar bagi karyawan untuk mencari pekerjaan. Menurut Beard (1986) dalam Khan dan Mufti (2012 : 4617) kompensasi dapat dibagi dalam tiga klasifikasi, yaitu fixed-pay, fleksible pay dan benefits. Sementara menurut Taylor (1991) masih dalam Khan dan Mufti (2012 : 4617) kompensasi dibagi dalam dua klasifikasi, yaitu Performance-based pay and Non-performance based pay.

Dalam klasifikasi pertama, fixed-pay (gaji tetap) adalah kompensasi yang diberikan kepada karyawan sebagai gaji pokoknya misalnya promosi, kenaikan tunjangan dan biaya hidup. Ini berada di bawah fixed-pay karena semua menjadi bagian dari gaji pokok karyawan. Fleksible-pay terdiri dari dua komponen di dalamnya yaitu variabel gaji dan deferred Income (komisi, bonus, pembagian keuntungan dan lain-lain). Besarnya fleksible-pay adalah variabel atau distribusi yang sifatnya tidak pasti, yang biasanya diberikan kepada tenaga penjual. Penghasilan tangguhan (fleksible-pay) adalah pembayaran jangka panjang pada skema organisasi misalnya kepemilikan bagi hasil, perusahaan tabungan rencana saham karyawan.

\section{Budaya Organisasi}

Schein (2002: 34) menyatakan bahwa "organizational culture is basic assumption pattern that is created, found, or developed by certain group when they adapting themselves with the external problems and internal integration work well and considered as worth, and taught to new members the correct way to realize, think, and feel the relation with the problems". Budaya organisasi adalah pola asumsi dasar yang diciptakan, ditemukan, atau dikembangkan oleh kelompok tertentu ketika mereka mengadaptasi diri dengan masalahmasalah eksternal dan integrasi internal bekerja dengan baik dan dianggap sebagai layak, dan diajarkan kepada anggota baru cara yang benar untuk mewujudkan, berpikir, dan merasa hubungan dengan masalah. Kemudian Robbins (2003: 271) mendefinisikan bahwa "organizational culture is collective meaning system that are followed by the members that differentiate the organization to others". Budaya organisasi adalah system kolektif yang diikuti oleh anggota organisasi yang membedakan organisasi dengan oragnisasi lainnya. Wallach (1983) dalam Jack Henry Syauta et al (2012: 70) budaya organisasi dikelompokkan menjadi tiga, yaitu: budaya birokrasi, budaya inovatif dan budaya supportif (mendukung). Budaya birokrasi adalah kondisi budaya yang perlu pengaturan, perintah dan aturan. Budaya inovatif merupakan budaya yang memberikan kebebasan berpikir, berpendapat, perasaan dan kebebasan bekerja kepada anggota organisasi. Dan budaya supportif (mendukung) adalah dalam Surat interaksi komunikasi memberikan penekanan pada nilai-nilai kekerabatan seperti harmoni, keterbukaan, persahabatan, kerjasama, dan kepercayaan.

\section{Kinerja Tenaga Ahli}

Prasetya dan Kato (2011) "performance is defined as the attained outcome of actions with the skills of employees who perform in some situation”. Kinerja didefinisikan sebagai hasil dicapai dari tindakan dengan keterampilan karyawan yang tampil di beberapa situasi. Mangkunegara dalam FR Yamali (2017) 
mendifinisikan "kinerja (performance) adalah hasil kerja secara kualitas dan kuantitas yang dicapai seorang pegawai dalam melaksanakan tugasnya sesuai dengan tanggung jawab yang diberikan kepadanya". Siagian dalam FR Yamali (2017), mendefinisikan kinerja pegawai sebagai suatu hasil kerja yang dicapai seseorang dalam melaksanakan tugas-tugas yang dibebankan kepadanya didasarkan atas kecakapan, pengalaman, kesungguhan serta waktu. Sehingga kinerja pegawai merupakan hasil kerja maksimal yang dicapai oleh pegawai dalam melaksanakan pekerjaannya yang didasarkan atas kecakapan, pengalaman dan kesungguhan serta waktu. Bohlander et al. (2001: 81) menyatakan bahwa "performance employee has been associated with the ability of the individual employees realizing their respective work goals, fulfilling expectations as well as attaining job targets and/or accomplishing a standard that are set by their organizations". Kinerja pegawai dikaitkan dengan kemampuan individu karyawan dalam mewujudkan tujuan kerja masing masing, memenuhi harapan serta mencapai target pekerjaan dan/atau mencapai standar yang ditetapkan oleh organisasi mereka. Yamali (2018) dalam penelitian nya "influence of Compensation, Competencies, Organizational Culture and Organizational Commitment together affect on the Experts Performance of 85\%”. Kompensasi, Kompetensi, Budaya Organisasi dan Komitmen Organisasi secara bersama-sama berpengaruh terhadap pada Kinerja Ahli sebesar $85 \%$

\section{Hipotesis Penelitian}

Hipotesis pada penelitian ini disusun dari kerangka pemikiran di atas sebagai berikut:

1. Terdapat pengaruh kompensasi tenaga ahli terhadap kinerja tenaga ahli pada perusahaan jasa konsultan di Provinsi Jambi

2. Terdapat pengaruh budaya organisasi terhadap kinerja tenaga ahli pada perusahaan jasa konsultan di Provinsi Jambi

3. Terdapat pengaruh kompensasi tenaga ahli dan budaya organisasi secara bersama-sama terhadap kinerja tenaga ahli pada perusahaan jasa konsultan di Provinsi Jambi

\section{METODE}

Sifat penelitian ini adalah bersifat deskriptif dan verifikatif. Mengingat sifat penelitian ini adalah deskriptif dan verifikatif yang dilaksanakan melalui pengumpulan data di lapangan, maka metode penelitian yang digunakan adalah metode descriptive survey dan metode explanatory survey. Unit analisis dalam penelitian ini adalah para tenaga ahli pada perusahaan jasa konsultan di Provinsi Jambi yang telah teregistrasi di Lembaga Pengembangan Jasa Konstruksi (LPJK) Provinsi Jambi.

\section{Sumber dan Cara Penentuan Data/ Informasi}

1. Penelitian kepustakaan (Library research), digunakan untuk mendapatkan data sekunder, yaitu pencarian bahan-bahan dan teori-teori dengan mempelajari, meneliti, mengkaji, serta menelaah literatur-literatur yang berhubungan dengan masalah yang akan diteliti.

2. Penelitian lapangan (Field research), digunakan untuk mendapatkan data primer, yaitu dengan mendatangi para tenaga ahli. Penelitian lapangan ini dilakukan dengan cara :Kuesioner, merupakan teknik pengumpulan data yang dilakukan dengan cara memberi seperangkat pernyataan tertulis untuk dijawabnya.

\section{Teknik Pengumpulan Data}

Penelitian ini merupakan penelitian persepsi dari objek penelitian, yang dalam hal ini adalah para tenaga ahli perusahaan jasa konsultan di Provinsi Jambi, oleh karenanya jenis data dalam penelitian ini adalah data subjek (self-report data). Sedangkan sumber data, yaitu (1) Sumber data sekunder adalah dari perusahaan jasa konsultan yang terdaftar di Provinsi Jambi, dan (2) Sumber data primer yaitu para tenaga ahli pada perusahaan jasa konsultan di Provinsi Jambi. Data yang diperlukan dari kedua jenis data tersebut dikumpulkan dengan teknik 1). Teknik Kuesioner. 2). Kuesioner, 3). Teknik Observasi. 4). Observasi, 5). Teknik Kepustakaan 


\section{Populasi dan Sampel}

Sugiyono (2013 : 61) populasi adalah wilayah generalisasi yang terdiri atas onyek/subyek yang mempinyai kualitas dan karakteristik tertentu yang ditetapkan peneliti untuk dipelajari/ diteliti dan kemudian ditarik kesimpulannya. Sementara Sekaran (2011:241) menyatkan bahwa populasi merupakan seluruh kelompok orang, peristiwa, atau hal yang ingin peneliti investigasi untuk penelitian. Dalam penelitian ini yang dijadikan populasi (unit analisis) adalah para tenaga ahli yang telah memiliki sertifikasi dari setiap perusahaan jasa konsultan yang terdaftar di LPJK Provinsi Jambi. Sampel adalah bagian dari jumlah dan karakteristik yang dimiliki oleh populasi (Sugiyono, 2013 : 62). Sementara Sakaran, 2011:244) menyatakan bahwa sampel adalah sub kelompok atau bagian dari populasi terdiri dari beberapa anggota terpilih dari populasi, dengan kata lain sebagian dari elemen populasi. Ukuran sampel yang digunakan memperhatikan teknik analisis yang digunakan dalam uji hipotesis yaitu model persamaan struktural (Structural Equation Model/SEM). Joreskog dan Sorbom (2001 : 32) menyatakan bahwa ukuran sampel yang diperlukan untuk analysis Strucural Equation Model adalah paling sedikit 200 pengamatan. Joreskog dan Sorbom (2001 : 32) menyatakan bahwa hubungan antara banyaknya variabel dan ukuran sampel dalam model persamaan dapat dilihat pada dapat dilihat pada tabel 3 .

Tabel 3.

Banyaknya Variabel dan Ukuran sampel Minimal Analisis Structural Equation Model (SEM)

\begin{tabular}{cc}
\hline Banyaknya Variabel & Ukuran Sampel \\
\hline 3 & 200 \\
5 & 200 \\
10 & 200 \\
15 & 360 \\
20 & 630 \\
25 & 975 \\
& \\
\hline
\end{tabular}

Sumber : Joreskog dan Sorbom (2001:32)

Dalam penelitian ini terdapat 3 variabel sehingga diperlukan ukuran sampel minimum sebesar 200 tenaga ahli. Dengan mempertimbangkan terdapatnya data outliers (Hair et al, 2006: 303) dan prinsip semakin besar ukuran sampel semakin baik.

\section{Rancangan Uji Instrumen Penelitian}

Mengingat sebagian data dalam penelitian ini adalah menggunakan data primer yang bersumber dari kuisioner, maka perlu dilakukan pengujian keabsahan atau kesahihan kuisioner sebagai alat ukurnya. Apabila alat ukur yang dipakai tidak valid atau tidak dapat dipercaya, maka hasil penelitian yang dilakukan tidak akan menggambarkan keadaan yang sesungguhnya. Untuk mengetahui keabsahan kuisioner sebagai alat ukur maka dilakukan uji validitas (test of validity) dan uji keandalan (test of reliability).

\section{Uji Validitas Instrumen Penelitian}

Tipe validitas yang digunakan adalah validitas konstruk (validity construct) yang menentukan validitas dengan cara mengkorelasikan antar skor yang diperoleh masing-masing item yang dapat berupa pertanyaan maupun pertanyaan dengan skor totalnya. Menurut Sugiyono, bila validitas tiap faktor tersebut positif dan besarnya 0,3 ke atas, maka faktor tersebut merupakan construct yang kuat atau valid (Sugiyono,2013: 356). Untuk mengukur tingkat validitas dari setiap item kuesioner digunakan software SPSS yang merupakan alat ukur dari penilaian.

\section{Uji Reliabilitas Instrumen Penelitian}

Reliabilitas menunjukan tingkat keterandalan tertentu. Reliabel artinya, dapat dipercaya, jadi dapat di andalkan. (Suharsimi, 2002: 154). Untuk melakukan uji reliabilitas, peneliti menggunakan rumus alpha. Jika nilai reliabilitas alpha lebih besar dari 0,7 maka instrument dapat dinyatakan reliable (Suharsimi, 2002: 171). 
Berdasarkan uji reliabilitas pada 30 orang responden (pre-test data), diperoleh nilai reliabilitas alpha pada setiap variabel memiliki nilai lebih besar dari 0.7, sehingga dengan demikian alat ukur/instrumen dapat dinyatakan Reliable

\section{Rancangan Analisis dan Uji Hipotesis}

Berdasarkan tujuan penelitian ini yaitu mengukur pengaruh dari variabel independen (kompensasi dan budaya organisasi) terhadap variabel dependen (kinerja tenaga ahli), maka pendekatan dalam pemodelan serta teknik solusi yang digunakan sebagai alat analisis (tools of analysis) di dalam disertasi ini adalah dengan menggunakan Structural Equation Model (SEM). Analisis Structural Equation model akan memberikan gambaran kejelasan hubungan dan besarnya pengaruh antara variabel penelitian yang sangat berguna untuk mengupas secara terinci berbagai faktor yang mampu meningkatkan kinerja tenaga ahli.

\section{HASIL}

Tabel 4

Indek Kesesuaian Model

\begin{tabular}{llccc}
\hline \multicolumn{1}{c}{ Indikator GOF } & \multicolumn{2}{c}{ Ukuran yang diharapkan } & Hasil Estimasi & Kesimpulan \\
\hline GFI & Ukuran Absolute Fit & & \\
RMSEA & GFI $>0,90$ & 0,95 & Good Fit \\
& RMSEA $<0,08$ & & 0,08 & Good Fit \\
NFI & NFI $>0,90$ & Ukuran Incremental Fit & & Good Fit \\
NNFI & NNFI $>0,90$ & 0,98 & Good Fit \\
AGFI & AGFI $>0,90$ & 0,98 & Good Fit \\
RFI & RFI $>0,90$ & 0,90 & Good Fit \\
IFI & IFI $>0,90$ & 0,97 & Good Fit \\
CFI & CFI $>0,90$ & 0,99 & Good Fit \\
\hline
\end{tabular}

Sumber : Hasil Pengolahan dengan LISREL 8.70

Model penuh persamaan SEM dengan menggunakan program LISREL 8.70 diperoleh dua model, yaitu model standardized dan model $t$-values, masing-masing model seperti ditunjukkan pada Gambar berikut:

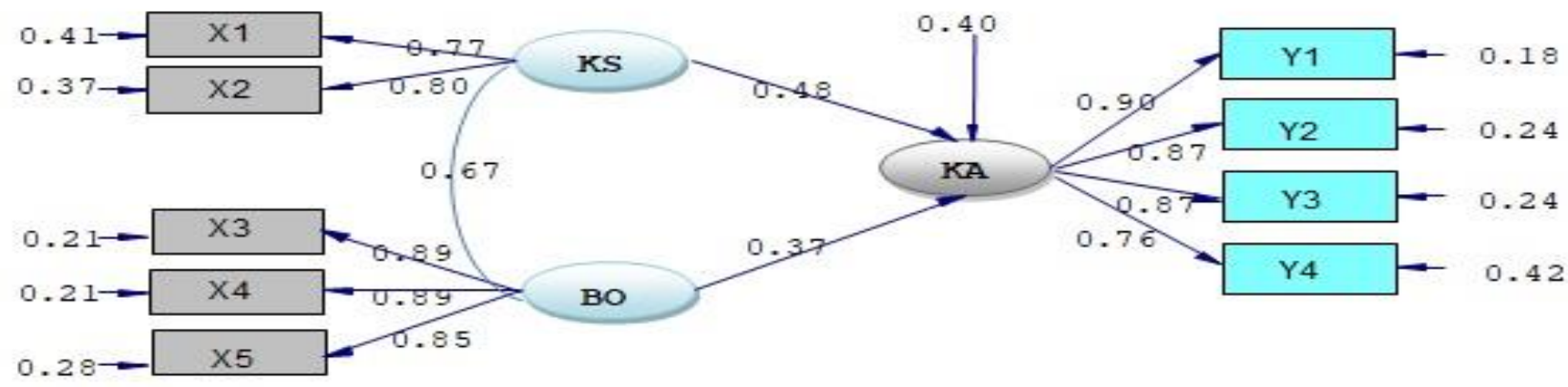

Chi-Square $=88.86, \mathrm{df}=24, \mathrm{P}-\mathrm{value}=0.00000$, RMSEA $=0.087$ 
Gambar 2.

Basic Model SEM (Standardized Model)

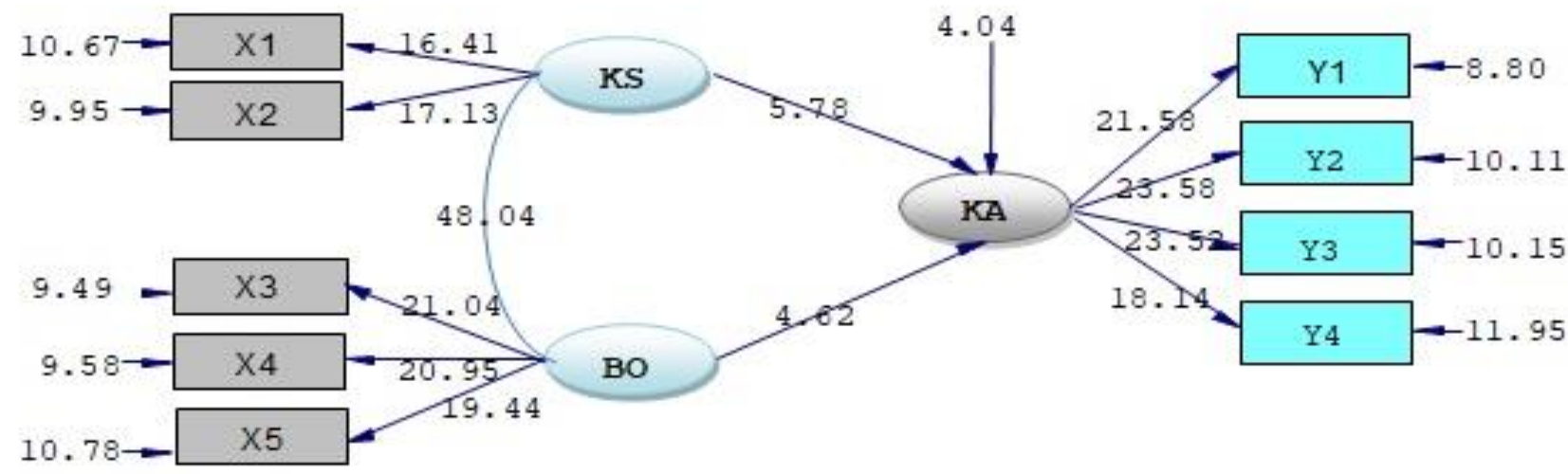

Chi-Square $=88.86, \mathrm{df}=24, \mathrm{P}-\mathrm{value}=0.00000, \mathrm{RMSEA}=0.087$

Keterangan: $\mathrm{KS}=$ Kompensasi; $\mathrm{BO}=$ Budaya organisasi; KA = Kinerja Tenaga Ahli

Gambar 3.

Basic Model SEM (t-Model)

Gambar 2 dan Gambar 3. di atas menggambarkan model full SEM, selanjutnya akan dikemukakan pengujian parameter $\lambda$ (loading factor/ koefisien indikator). Pengujian parameter $\lambda$ adalah koefisien regresi terstandarisasi (standardized regression weight) untuk variabel eksogen maupun endogen seperti ditunjukkan pada Tabel 5. berikut.

Tabel 5

Uji Statistik Model Pengukuran

\begin{tabular}{|c|c|c|c|c|c|c|}
\hline \multicolumn{2}{|c|}{ Measurement Model } & \multirow[b]{2}{*}{$\begin{array}{l}\text { Loading } \\
\text { Factor }\end{array}$} & \multirow[b]{2}{*}{$\begin{array}{c}\text { Standard } \\
\text { Error }\end{array}$} & \multirow[b]{2}{*}{ t hitung } & \multirow{2}{*}{$\begin{array}{c}\text { Constuk } \\
\text { Reliablilty } \\
(\text { CR })\end{array}$} & \multirow{2}{*}{$\begin{array}{c}\text { Variance } \\
\text { Extract } \\
(V E)\end{array}$} \\
\hline $\begin{array}{c}\text { Latent } \\
\text { Variable }\end{array}$ & $\begin{array}{c}\text { Manifest } \\
\text { Variable }\end{array}$ & & & & & \\
\hline \multirow{7}{*}{ Kompensasi } & Kompensasi & 0.77 & 0.038 & 16.41 & \multirow{7}{*}{0.9822} & \multirow{7}{*}{0.9321} \\
\hline & Langsung (X1) & & & & & \\
\hline & Kompensasi & & & & & \\
\hline & Tiadak & 0.80 & 0.037 & 17.13 & & \\
\hline & Langsung (X2) & & & & & \\
\hline & Kompetensi & 0.89 & 0.022 & 21.04 & & \\
\hline & Kognitif (X3) & & & & & \\
\hline \multirow{3}{*}{$\begin{array}{l}\text { Budaya } \\
\text { Organisasi }\end{array}$} & Kompetensi & 0.89 & 0.022 & 20.95 & \multirow{3}{*}{0.9245} & \multirow{3}{*}{0.9854} \\
\hline & Fungsional (X4) & & & & & \\
\hline & $\begin{array}{l}\text { Kompetensi } \\
\text { Sosial (X5) }\end{array}$ & 0.85 & 0.026 & 19.44 & & \\
\hline \multirow{4}{*}{$\begin{array}{c}\text { Kinerja } \\
\text { Tenaga Ahli }\end{array}$} & $\begin{array}{l}\text { Kualitas Kerja } \\
\text { (Y1) }\end{array}$ & 0.90 & 0.021 & 21.58 & \multirow{4}{*}{0.9464} & \multirow{4}{*}{0.9556} \\
\hline & Kuantitas Kerja & 0.87 & 0.024 & 23.58 & & \\
\hline & $\begin{array}{l}\text { (Y2) } \\
\text { Keandalan } \\
\text { (Y3) }\end{array}$ & 0.87 & 0.024 & 23.52 & & \\
\hline & $\begin{array}{l}\text { Sikap } \\
\text { (Y4) }\end{array}$ & 0.76 & 0.036 & 18.14 & & \\
\hline
\end{tabular}

Sumber : Hasil Pengolahan Data, 2018 ( LISREL 8.70)

Tabel 5. di atas, terlihat bahwa semua manifest (dimensi) memiliki Standardized Loading Factor (SLF) $\geq 0,50$ dan nilai $\left|t_{\text {kritis }}\right| \geq 1,96$ atau $\left|t_{\text {kritis }}\right| \geq 2$ (pada $\alpha=0,05$ ) (Wijanto, 2008), maka semua manifest pembentuk variabel latent (eksogen dan endogen) adalah signifikan, dengan kata lain dapat dikatakan bahwa 
manifest-manifest bermakna dan signifikan dalam membentuk variabel laten. Sehingga semua manifest dalam penelitian ini dapat di analisis lebih lanjut, karena sudah dapat membentuk variabel latennya. Validitas semua sub variabel diatas merupakan indikator dengan standardized loading factor dengan taksiran parameter dalam membentuk semua variabel. Construct reliability dan variance extract semua variabel menunjukkan bahwa konstruk variabel memiliki konstruk reliabilitas yang baik.

Tabel 6.

Uji Statistik Model Struktural

\begin{tabular}{|c|c|c|c|c|c|}
\hline \multicolumn{2}{|c|}{ Structure Model } & \multirow{2}{*}{$\begin{array}{c}\text { Coefficient } \\
\text { Factor } \\
\text { (Standarized) }\end{array}$} & \multirow[b]{2}{*}{$\begin{array}{c}\text { Standard } \\
\text { Error }\end{array}$} & \multirow{2}{*}{$\begin{array}{l}\text { thitung/ } \\
\text { F hitung }\end{array}$} & \multirow{2}{*}{$\begin{array}{l}\text { Hasil Uji } \\
\text { Hipotesis }\end{array}$} \\
\hline $\begin{array}{c}\text { Varible } \\
\text { Endogen } \\
\end{array}$ & $\begin{array}{c}\text { Variable } \\
\text { Eksogen/Endogen } \\
\end{array}$ & & & & \\
\hline Kinerja Tenaga & Kompesasi & 0.48 & 0.078 & 5.78 & Sig. (Parsial) \\
\hline Ahli & Budaya Organisasi & 0.37 & 0.070 & 4.62 & Sig. (Parsial) \\
\hline
\end{tabular}

Sumber : Hasil Pengolahan Data, 2018

Hasil pengujian diperoleh kesimpulan bahwa semua hipotesis dari ketiga hipotesis penelitian diterima. Pengujian hipotesis tentang pengaruh variabel Kompensasi (KS) terhadap variabel Kinerja Tenaga Ahli (KA). Sesuai dengan hipotesis yang diajukan dapat dilihat seperti persamaan struktural di bawah ini.

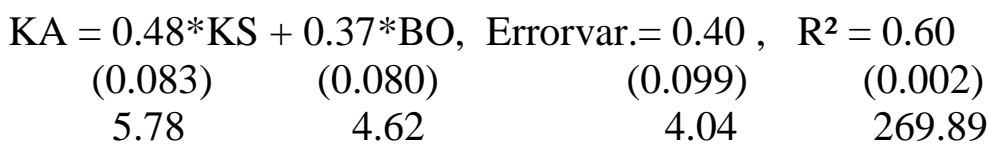

Persamaan struktural $1 \mathrm{di}$ atas, terlihat besarnya loading factor (koefisien jalur) variabel Kompensasi terhadap Kinerja Tenaga Ahli adalah sebesar 0,48. dan Variabel Budaya Organisasi adalah sebesar 0,37. Persamaan di atas menjelaskan, ternyata nilai thitung dari pengaruh Kompensasi dan Budaya Organisasi terhadap Kinerja Tenaga Ahli adalah sebesar 5,78 dan 4,62 > 1,96, sehingga dapat dikatakan signifikan, dengan demikian Kompensasi dan Budaya Organisasi berpengaruh positif dan signifikan terhadap Kinerja Tenaga Ahli pada Perusahaan Jasa Konsultan di Provinsi Jambi. Artinya semakin baik Kompensasi dan Budaya Organisasi pada Perusahaan Jasa Konsultan di Provinsi Jambi, maka Kinerja Tenaga Ahli Perusahaan Jasa Konsultan di Provinsi Jambi akan semakin meningkat/ tinggi, maka dengan demikian Hipotesis 1 dan 2 diterima.

Persamaan 1 di atas juga menjelaskan, ternyata nilai $F_{\text {hitung }}$ dari pengaruh Kompensasi dan Budaya organisasi secara bersama-sama terhadap Kinerja Tenaga Ahli adalah sebesar 269,89> 3,84, sehingga dapat dikatakan signifikan, dengan demikian Kompensasi dan Budaya organisasi secara bersama-sama berpengaruh positif dan signifikan terhadap Kinerja Tenaga Ahli, maka dengan demikian Hipotesis 3 diterima. Adapun besar pengaruh secara bersama-sama variabel Kompensasi, Kompetensi dan Budaya organisasi terhadap Komitmen Organisasi adalah sebesar 60\%, sisanya sebesar $40 \%$ dipengaruhi oleh faktor lain, seperti faktor kompetensi, komitnen organisasi, pemberdayaan, keterikatan pegawai, disiplin pegawai, motivasi dan lainlain. Dengan demikian dapat disimpulkan Kinerja Tenaga Ahli Perusahaan Jasa Konsultan di Provinsi Jambi dipengaruhi secara positif dan signifikan oleh Kompensasi dan Budaya organisasi.

Hasil pengujian hipotesis di atas, dapat dilihat dengan besarnya pengaruh langsung dan tidak langsung Kompensasi dan Budaya organisasi terhadap Kinerja Tenaga Ahli Perusahaan Jasa Konsultan di Provinsi Jambi seperti berikut: 
Tabel 7.

Hasil Perhitungan Besar Pengaruh Langsung dan Tidak Langsung Kompensasi (KS) dan Budaya Organisasi (BO) terhadap Kinerja Tenaga Ahli (KA)

\begin{tabular}{|c|c|c|c|c|}
\hline \multirow[t]{2}{*}{ Variabel } & \multicolumn{4}{|c|}{ Besar Pengaruh } \\
\hline & Langsung & Tidak Langsung & Ket. & Total \\
\hline \multirow[t]{2}{*}{ Kompensasi (KS) } & 0.2304 & & & 0.3494 \\
\hline & & 0.1190 & melalui BO & \\
\hline \multirow[t]{2}{*}{ Budaya Organisasi (BO) } & 0.1369 & & & 0.2559 \\
\hline & & 0.1190 & melalui KS & \\
\hline \multicolumn{3}{|c|}{ Pengaruh Secara bersama-sama KS, BO terhadap KA } & $R^{2} K S, B O$ & 0.6053 \\
\hline \multicolumn{3}{|c|}{ Pengaruh Variabel luar terhadap KA } & $\zeta_{1}$ & 0.3947 \\
\hline
\end{tabular}

Sumber : Hasil Pengolahan Data, 2018 (LISREL 8.70)

Tabel 7. di atas menjelaskan, Pengaruh secara bersama-sama Kompensasi (KS) dan Budaya Organisasi (BO) terhadap Kinerja Tenaga Ahli $(\mathrm{KA})$ adalah $0.6053 \approx 0.60$ atau merupakan $\mathrm{R}^{2}=0.60$. Atas dasar perhitungan di atas, maka dapat dikemukakan hal-hal sebagai berikut:

1) Besar kontribusi pengaruh langsung variabel Kompensasi terhadap variabel Kinerja Tenaga Ahli adalah dengan kontribusi sebesar 23,04\%. Sementara besar kontribusi pengaruh tidak langsung Kompensasi terhadap Kinerja Tenaga Ahli melalui Budaya Organisasi adalah sebesar 11,90\%, sehingga total kontribusi pengaruh variabel Kompensasi terhadap variabel Komitmen Organisasi adalah sebesar $34,94 \%$.

2) Besar kontribusi pengaruh langsung variabel Budaya Organisasi terhadap variabel Kinerja Tenaga Ahli adalah sebesar 25,59\%. Sementara besar kontribusi pengaruh tidak langsung Budaya Organisasi terhadap Kinerja Tenaga Ahli melalui Kompensasi adalah sebesar 11,90\%, sehingga total kontribusi pengaruh variabel Budaya Organisasi terhadap variabel Kinerja Tenaga Ahli adalah sebesar 25,59\%.

3) Mengacu pada uraian 1 dan 2 di atas, maka total pengaruh yang paling dominan terhadap kinerja tenaga ahli adalah faktor Kompensasi dengan kontribusi sebesar 34,94\% daripada faktor Budaya Organisasi yang hanya sebesar $25,59 \%$.

Hasil pengujian di atas menunjukkan bahwa variabel Kompensasi dan Budaya Organisasi berpengaruh terhadap variabel Kinerja Tenaga Ahli dengan kontribusi sebesar 60\%. Berdasarkan pengujian hipotesishipotesis di atas, maka bisa dikatakan bahwa untuk meningkatkan Kinerja Tenaga Ahli Perusahaan Jasa Konsultan di Provinsi Jambi terutama pada dimensi-dimensi nya (kulaitas kerja, kuantitas kerja, keandalan dan sikap) mampu ditingkatkan jika Perusahaan Jasa Konsultan di Provinsi Jambi mampu meningkatkan kompensasi dan budaya organisasi terutama pada variabel kompensasi tenaga ahli.

\section{SIMPULAN}

Hasil penelitian dapat disimpulkan sebagai berilkut:

1. Kompensasi secara parsial berpengaruh positif dan signifikan terhadap Kinerja tenaga ahli, artinya bahwa peningkatan Kompensasi tenaga ahli akan mengakibatkan meningkatnya Kinerja tenaga ahli pada tenaga ahli Perusahaan Jasa Konsultan di Provinsi Jambi. Dimensi yang paling dominan dalam membentuk variabel Kompensasi tenaga ahli adalah dimensi Kompensasi Tidak Langsung.

2. Budaya Organisasi secara parsial berpengaruh positif dan signifikan terhadap Kinerja tenaga ahli, artinya bahwa peningkatan Budaya Organisasi akan mengakibatkan meningkatnya Kinerja tenaga ahli pada tenaga ahli Perusahaan Jasa Konsultan di Provinsi Jambi. Dimensi paling dominan dalam membentuk variabel Budaya organaisasi adalah dimensi Budaya Birokrasi dan Budaya Afektif yang benrnilai sama.

3. Sementara dimensi yang paling dominan dalam membentuk variabel Kinerja tenaga ahli adalah dimensi Kuantitas kerja.

4. Kompensasi dan Budaya Organisasi secara bersama-sama berpengaruh positif dan signifikan terhadap Kinerja Tenaga Ahli pada tenaga ahli Perusahaan Jasa Konsultan di Provinsi Jambi dengan nilai koefisien determinasi $\left(\mathrm{R}^{2}\right)$ sebesar 60\%, hal ini menunjukkan bahwa 60\% variabel Kinerja tenaga ahli mampu 
dijelaskan secara bersama-sama oleh variabel Kompensasi dan Budaya Organisasi sementara 40\% dipengaruhi variabel selain Kompensasi dan dan Budaya Organisasi. Peningkatan Kompensasi dan Budaya Organisasi akan mengakibatkan meningkatnya Kinerja tenaga ahli.

\section{DAFTAR PUSTAKA}

Alhudhori, M. dan Aldino, W., , 2017, Pengaruh Kepemimpinan dan Disiplin terhadap Motivasi Kerja Serta Dampaknya pada Kinerja Pegawai Rumah Sakit Umum Bersaudara Kabupaten, Jurnal Manajemen dan Sains (JMAS), 2(1), 23-32

Awadh, Alharbi Mand Saad, Alyahya M. 2013. "Impact of Organizational Culture on Employee Performance". International Review of Management and Business Research. Vol. 2 Issue. 1

Bohlander, G., Snell, S., \& Sherman, A. 2001. "Managing human resources”. Australia: South-Western College Publishing.

Hair et al., 2006, “Multivariate Data Analysis”, Fifth Edition, New Jersey. Prentice Hall, Upper Saddle River. Jack Henry Syauta, Eka Afnan Troena, Margono Setiawan, dan Solimun. 2012. "The Influence of Organizational Culture, Organizational Commitment to Job Satisfaction and Employee Performance" (Study at Municipal Waterworks of Jayapura, Papua Indonesia). International Journal of Business and Management Invention ISSN (Online): 2319 - 8028, ISSN (Print): 2319 - 801X, Volume 1Issue 1, December. 2012 PP.69-76

Jamil, Bilal and Sarfaraz, Naintara Raja. 2011. "Impact of Compensation, Performance Evaluation and Promotion Practices on Government Employees Performance VS Private Employees Performance". Interdisciplinary Journal Of Contemporary Research In Business December, Vol 3, No 8

Jane Nelima Wekesa and Silas Nyaroo. 2013. "Effect of Compensation on Performance of Public Secondary School Teachers in Eldoret Municipality Kenya". International Journal of Scientific and Research Publications, Volume 3, Issue 6, June 20131 ISSN 2250-3153

Jöreskog, Karl G. and Dag Sörbom. 2001. “LISREL 8: User's Reference Guide”. Lincoln wood, IL: Scientific Software International, Inc.

Khan, Waqas and Mufti, Owais. 2012. "Effect of Compensation on Motivating Employees in Public and Private Banks of Peshawar (BOK and UBL)". Journal of Basic and Applied Scientific Research, ISSN 2090-4304, 2(5)4616-4623, 2012

Kementerian PU. 2013. "Perkembangan Standar Kompetensi Kerja Nasional Indonesia (SKKNI) Jasa Konstruksi" Jakarta. Edisi II. Buletin Badan Pembinaan Konstruksi. ISSN 1907-0136

LPJK Provinsi. 2016. “Laporan Akhir Tahun”, Jambi. Lembaga Pengembangan Jasa Konstruksi.

Prasetya, A. and Kato, M. 2011. "The Effect of Financial and Non Financial Compensation to the Employee

Performance”.Yogyakarta, Indonesia. The 2nd International Research Symposium in Service Management.

Robbins, Stephen P. 2003. “Organizational Behaviour”. Ninth Edition, New Jersey: Prentice Hall International Inc.

Schein, E.H. 2002. “Organizational Culture and Leadership: a Dynamic View”. San Francisco: Jossey-Bass. Sekaran, Uma. 2000. "Research Methods For Business", Third Edition, Jhon Wiley \& Sons, Inc: New York. Sugiyono, 2013, "Statistika untuk Penelitian”, Bandung. Alfa Beta.

Suharsimi, Arikunto, 2002, "Prosedur Penelitian Suatu Pendekatan Praktek”, Jakarta: Rineka Cipta.

Tahir Masood Quershi. 2010. "Relationship between HR Practices and Perceived Employees' Performance of Bankers in NWFP Pakistan”(An Empirical Evidence). African Journal of Business Management Vol. 4(7), pp. 1281-1288.

Yamali FR, 2017, "Kompensasi dan Kmpetensi terhadap Komitmen Organisasi serta Implikasinya pada Kinerja Tenaga Ahli Perusahaan Jasa Konstruksi Di Provinsi Jambi ”Journal of Economic and Businees, LPPM Unbari Jambi.

Yamali FR, 2018, "Effect of Compensation, Competencies and Organizational Culture on Organizational Commitment its Implicationson Experts Performance of Construction Services Company in Jambi 
Province. International Journal of Advances in Management and Economics (IJAME) Maret 2018 Vol.7(2) ISSN : 2278-3369 